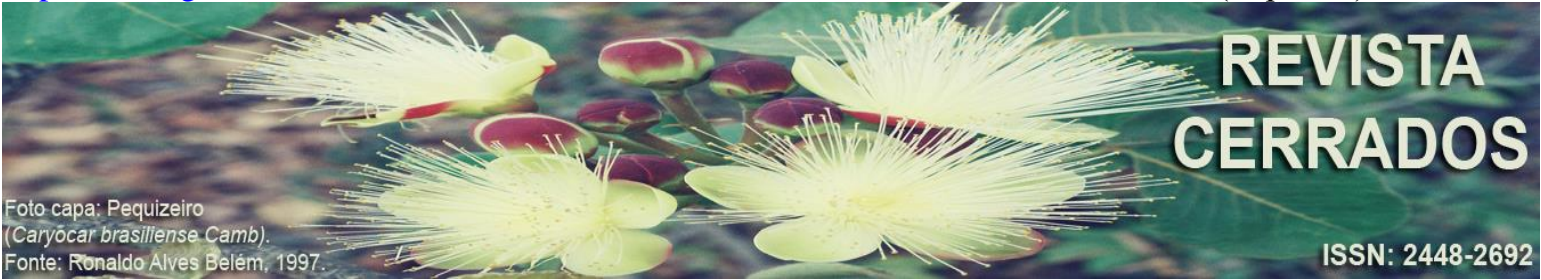

\title{
HERANÇAS DA PAISAGEM SEMIÁRIDA: Os Relevos Residuais de Alexandria-RN, Brasil
}

\section{HERITIES OF THE SEMI-ARID LANDSCAPE: The Residual Reliefs of Alexandria-RN, Brazil}

\section{HERENCIAS DEL PAISAJE SEMIÁRIDO: Los Relieves Residuales de Alexandria-RN, Brasil}

\begin{abstract}
Diógenys da Silva Henriques
Universidade do Estado do Rio Grande do Norte - UERN, Pau dos Ferros,

Rio Grande do Norte, Brasil E-mail: <diogenyshenriques@outlook.com>.

Anny Catarina Nobre de Souza

Universidade do Estado do Rio Grande do Norte - UERN, Pau dos Ferros,

Rio Grande do Norte, Brasil E-mail: <anny-catarina13@hotmail.com>.

Sérgio Domiciano Gomes de Souza

Universidade do Estado do Rio Grande do Norte - UERN, Pau dos Ferros,

Rio Grande do Norte, Brasil

E-mail: 〈sergio_gsousa@hotmail.com>.

Maria Losângela Martins de Sousa

Universidade do Estado do Rio Grande do Norte - UERN, Pau dos Ferros,

Rio Grande do Norte, Brasil

E-mail: <losangelaufc@gmail.com>.
\end{abstract}

\begin{abstract}
RESUMO
O presente artigo objetiva discutir acerca dos relevos residuais do semiárido nordestino, enfocando um estudo de caso realizado no município de Alexandria no Alto Oeste Potiguar, Rio Grande do Norte, através do qual apresenta-se como heranças das feições geomorfológicas marcantes da paisagem semiárida do sertão do oeste potiguar nordestino. No tocante os procedimentos metodológicos, a pesquisa é sistematizada em duas etapas: gabinete - levantamento bibliográfico e geocartográfico - e campo - visita e reconhecimento da área em estudo. Consideramos assim os estudos teóricos de Ab'Saber (2003), Bertrand (2004), Lima et. al. (2009), Maia e Nascimento (2015; 2018), Souza e Oliveira (2002), além de
\end{abstract}


HENRIQUES, D. S.; SOUZA, A. C. N.; SOUZA, S. D. G.; SOUSA, M. L. M.

Heranças da paisagem semiárida: Os relevos residuais de Alexandria-RN, Brasil.

interpretações cartográficas acerca das características geológico-geomorfológicas da área com base na CPRM (2005). Neste trabalho, verificamos a presença de relevos residuais predominantes, bem como extensas áreas de lajedos, que conferem uma paisagem exuberante no interior do sertão potiguar nordestino, de uma morfologia granítica, resultante do processo formativo de processos endógenos e exógenos, como resposta à constituição da paisagem como herança, sobretudo os inselbergs.

Palavras-chave: Paisagem semiárida. Feições geomorfológicas. Inselbergs.

\begin{abstract}
This article aims to discuss about the residual reliefs of the semi-arid northeast, focusing on a case study conducted in the municipality of Alexandria in the Upper West Potiguar, Rio Grande do Norte, through which it presents as inheritances of the remarkable geomorphological features of the semiarid landscape of the sertão of the western northeastern region. Regarding methodological procedures, the research is systematized in two stages: office - bibliographic and geocartographic survey - and field - visit and recognition of the study area. We thus consider the theoretical studies of Ab'Saber (2003), Bertrand (2004), Lima et. al. (2009), Maia and Nascimento (2015; 2018), Souza and Oliveira (2002), in addition to cartographic interpretations about the geological and geomorphological characteristics of the area based on CPRM (2005). In this work, we verified the presence of predominant residual reliefs, as well as extensive areas of flagstones, that give an exuberant landscape in the interior of the northeastern hinterland of Rio Grande do Norte, with a granitic morphology, resulting from the formative process of endogenous and exogenous processes, in response to the constitution of the landscape as an inheritance, especially the Inselbergs.
\end{abstract}

Keywords: Semi-arid landscape. Geomorphological features. Inselbergs.

\title{
RESUMEN
}

Este artículo tiene como objetivo discutir los relieves residuales de la región semiárida nororiental, centrándose en un estudio de caso realizado en el municipio de Alejandría en el Alto Oeste de Potiguar, Rio Grande do Norte, a través del cual se presenta como herencias de las llamativas características geomorfológicas de la paisaje semiárido del interior del noreste potiguar oeste. En cuanto a los procedimientos metodológicos, se sistematiza en dos etapas: gabinete - encuesta bibliográfica y geocartográfica - y campo - visita y reconocimiento de la zona en estudio. Por lo tanto, consideramos los estudios teóricos de Ab'Saber (2003), Bertrand (2004), Lima et al. (2009), Maia y Nascimento (2015; 2018), Souza e Oliveira (2002), además de interpretaciones cartográficas sobre las características geológicas geomorfológicas de la zona basadas en el CPRM (2005). En este trabajo, verificamos la presencia de relieves residuales predominantes, así como extensas áreas de losas, que confieren un exuberante paisaje en el interior noreste potiguar, de una morfología granítica resultante del proceso formativo de procesos endógeno y exógeno, como respuesta a la constitución del paisaje como herencia, especialmente los Inselbergs.

Palabras-clave: Paisaje semiárido. Características geomorfológicas. Inselbergs. 
HENRIQUES, D. S.; SOUZA, A. C. N.; SOUZA, S. D. G.; SOUSA, M. L. M.

Heranças da paisagem semiárida: Os relevos residuais de Alexandria-RN, Brasil.

\section{INTRODUÇÃO}

A paisagem é uma unidade natural na dimensão do espaço geográfico. Esta, por sua vez, caracteriza-se pela constituição de elementos que, em uma ação de simbiose, lhe confere peculiaridades únicas. Por esta razão, a paisagem é heterogênea, variando de acordo com as qualidades naturais de cada ambiente e não sendo a simples separação dos elementos físicos, biológicos e antrópicos, mas o resultado da interação destes, em constante evolução (BERTRAND, 2004).

De acordo com Ab'Saber (2003), esta pode ser entendida ainda como uma herança, pois resulta de processos historicamente ocorridos, de prevalência natural e humana, haja vista que esse segundo elemento constrói o espaço geográfico e, por consequência, modifica e recria a paisagem, com o passar dos tempos.

O entendimento da paisagem abordada neste papper é de essência geoambiental, à luz de fatores físico-naturais, somado ao componente humano. Versa-se sobre uma paisagem condicionada em um ambiente de semiaridez, com características bem peculiares na configuração dos domínios naturais do território brasileiro. Em particular, trata-se das feições geomorfológicas associadas aos relevos residuais, como enclaves no semiárido brasileiro. Em relação aos aspectos naturais que condicionam a paisagem do semiárido nordestino, cabe considerar que o Nordeste é a região de maior diversidade de quadros ambientais, porém o que a "singulariza em relação às demais regiões é a grande parcela de terras submetidas ao semi-árido. O Nordeste contém a totalidade do semi-árido brasileiro" (SOUZA; OLIVEIRA, 2002, p. 207).

Nesse ínterim, discute-se acerca da paisagem semiárida e de sua configuração geoambiental, dando ênfase aos inselbergs, como feições geomorfológicas presentes no ambiente nordestino com marcas representativas de um passado geológico, que, por ocasião das variáveis naturais associadas ao clima semiárido, se configuram como tais.

Por isso, entende-se o semiárido como uma região natural com características que lhe conferem um perfil de exceção no território brasileiro. Isso porque suas condições naturais estão associadas à um clima quente e seco, com temperaturas que atingem a máxima de $38^{\circ} \mathrm{C}$ e índices pluviométricos que não ultrapassam a média dos $900 \mathrm{~mm}$ ao longo do ano. Resultante disso, de acordo com Duque (2004), a vegetação é, em geral, caatinga, caracterizada por um xerofilismo, que perde as folhas durante os períodos mais secos do ano, 
HENRIQUES, D. S.; SOUZA, A. C. N.; SOUZA, S. D. G.; SOUSA, M. L. M.

Heranças da paisagem semiárida: Os relevos residuais de Alexandria-RN, Brasil.

junto a qual se entrelaçam cactáceas de espécies, regionalmente conhecidas como xique-xique e mandacaru (cientificamente Pilosocereus gounellei e Cereus jamacaru, respectivamente). Ambas recobrem um relevo que varia entre a depressão sertaneja e relevos residuais marcados por serras e inselbergs.

Dessa forma, o presente artigo, objetiva discutir acerca dos relevos residuais do semiárido nordestino, enfocando um estudo de caso realizado no município de Alexandria, Rio Grande do Norte, que apresenta heranças das feições geomorfológicas marcantes da paisagem semiárida do sertão do Oeste potiguar nordestino.

O papper surge a partir de discussões acerca dos inselbergs no Nordeste brasileiro, no âmbito do Grupo de Estudos Análise Geoambiental da Paisagem (GEAGEIP) da Universidade do Estado do Rio Grande do Norte (UERN), Campus Avançado de Pau dos Ferros (CAPF). No tocante aos procedimentos metodológicos, a pesquisa está sistematizada em duas etapas: gabinete e campo. A primeira voltada ao levantamento bibliográfico e geocartográfico e a segunda como trabalho de campo no reconhecimento da verdade terrestre.

Subsidiado de uma revisão bibliográfica acerca da paisagem semiárida e dos inselbergs no Nordeste brasileiro, este trabalho encontra-se embasado nas contribuições teóricas de autores como Ab'Saber (2003), Souza e Oliveira (2002), Bertrand (2004), Lima et al. (2009), Maia e Nascimento (2015; 2018) e Oliveira (2018), bem como de interpretações cartográficas acerca das características geológico-geomorfológicas da área com base na CPRM (2005). Assim, para construção desse trabalho, realizou-se uma visita de campo no lócus de estudo, município de Alexandria ( $\mathrm{RN}$ ), para se conhecer a paisagem local e identificar as feições geomorfológicas ocorrentes doravante.

Desse modo, este trabalho encontra-se organizado em quatro seções. A primeira compreende uma contextualização do relevo paisagístico do Nordeste semiárido brasileiro, com destaque para a presença característica dos inselbergs. A segunda consiste na caracterização e localização do município de Alexandria, como lócus do estudo de caso. $\mathrm{Na}$ terceira, considerando os registros de campo, discutimos as feições geomorfológicas identificadas no referido município, por meio do contexto paisagístico revelado. Na quarta faz-se uma correlação da geodiversidade e do potencial da paisagem de Alexandria a essa vertente. Ao final, são realizados comentários finais sobre a temática analisada neste trabalho, de modo a traçar as suas contribuições. 
HENRIQUES, D. S.; SOUZA, A. C. N.; SOUZA, S. D. G.; SOUSA, M. L. M.

Heranças da paisagem semiárida: Os relevos residuais de Alexandria-RN, Brasil.

\section{GEOMORFOLOGIA DA PAISAGEM SEMIÁRIDA BRASILEIRA E A OCORRÊNCIA DE INSELBERGS}

A paisagem semiárida brasileira possui suas peculiaridades e singularidades, conforme foi mencionado anteriormente, e isso transcende os estereótipos regionais muito propagados. Conforme Silva et al. (2010), os sertões são marcados, caracteristicamente, por uma diversidade de paisagens e ambientes naturais. Os elementos naturais que os compõem geologia, geomorfologia, clima, hidrografia, pedologia e biogeografia - não podem ser entendidos dissociados ou isoladamente, uma vez que são interdependentes entre si. Pertinente a alguns aspectos naturais da região, os autores ponderam que, relativo à vegetação, a caatinga está arraigada em seus espaços e se adapta às intempéries naturais, seja em tempos de estiagens ou durante a quadra chuvosa.

A geologia é predominantemente cristalina, com rochas ígneas e metamorfisadas, porém é considerável a extensão das áreas de embasamento sedimentar. Como indica Cunha et al. (2010), existe em menor proporção, áreas cristalinas com cobertura pouco espessa de sedimentos arenosos ou arenoargilosos. Outrossim, as condições mineralógicas existentes, somada ao clima e as formações vegetais, exercem grande papel na formação variada dos solos do Nordeste brasileiro, conforme explicita a Figura 01.

Os solos mencionados no gráfico acima destacam-se por vulnerabilidades, mas também possuem potencialidades. A título de exemplo, os latossolos, classe predominante no Nordeste Brasileiro, que são solos bem desenvolvidos e possuem boa capacidade para retenção de água, embora sua fertilidade natural é caracterizada como baixa e comprometedora. No entanto, essa limitação não impede de ser utilizado para atividades de cultura irrigadas ou para pastagem de animais. Os Neossolos, por sua vez, também possuem limitações quanto ao uso agrícola, em razão da sua fertilidade natural também ser reduzida, mas é um material substancial para as construções civis.

Em contrapartida as demais regiões brasileiras, o semiárido apresenta variabilidade nos índices pluviométricos com pouco ou nenhum excedente hídrico anual. A região é marcada por longos anos de estiagem e distribuição irregular das chuvas, fator natural que compromete e agrava substancialmente o quadro socioeconômico da população que sobrevive, principalmente, de práticas agropecuárias. Considerando esse quadro, ainda é discutível a importância das ações e planos de convivência com o semiárido, as quais veem 
HENRIQUES, D. S.; SOUZA, A. C. N.; SOUZA, S. D. G.; SOUSA, M. L. M.

Heranças da paisagem semiárida: Os relevos residuais de Alexandria-RN, Brasil.

sendo desenvolvidas paralelas às ações de combate à seca (SOUSA; OLIVEIRA, 2011), embora estas não sejam suficientes para sanar a problemática que ainda persiste nos sertões semiáridos do Nordeste brasileiro.

Figura 1: Gráfico dos principais solos da Região Nordeste do Brasil

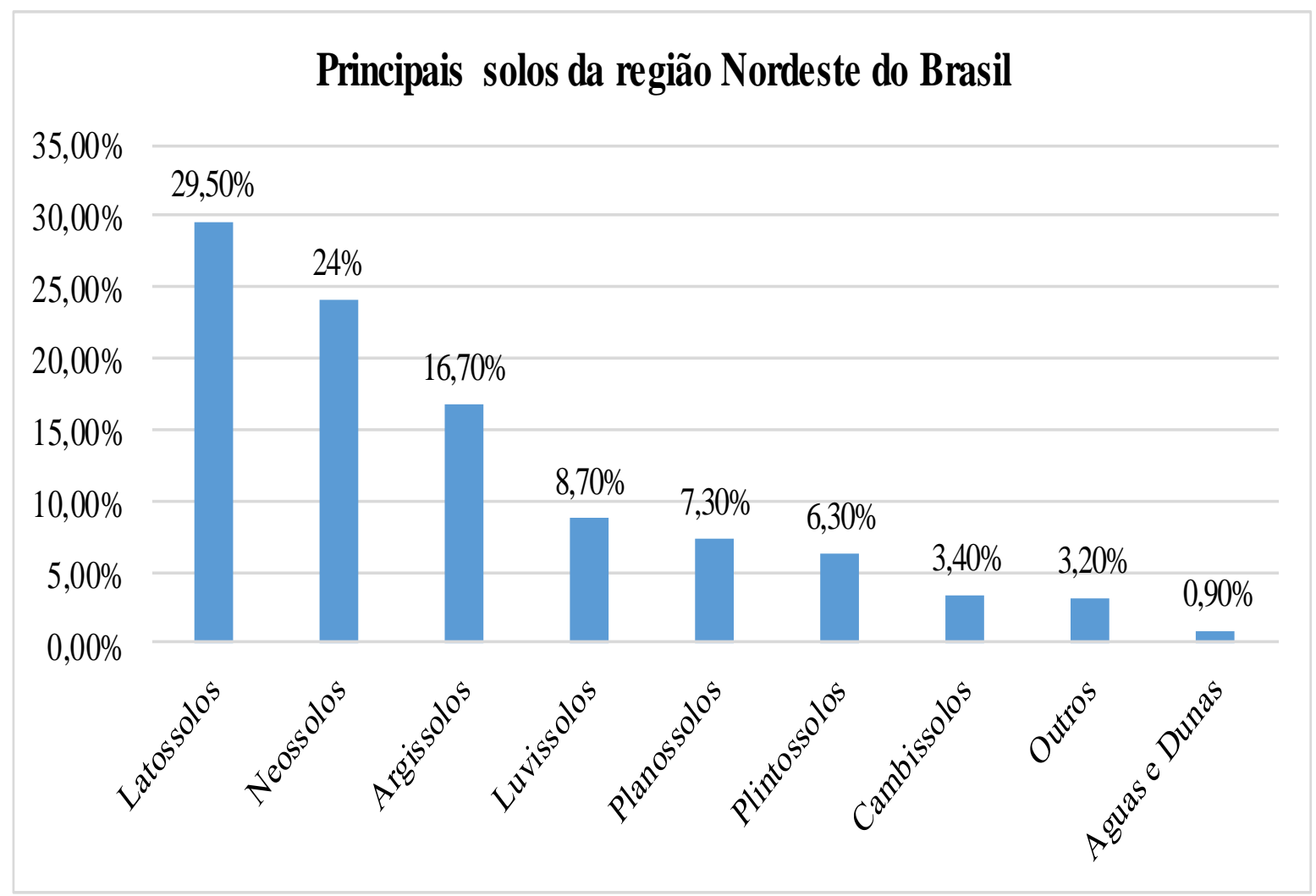

Fonte: Adaptado de Marques et al., 2014.

No tocante à geomorfologia, as formas de relevo, integradas aos outros aspectos naturais, consolidam quadros paisagísticos apolínicos, por vezes de exuberância inquestionável. São múltiplos os estudos acerca da evolução geomorfológica do Nordeste. Conforme enfocam Maia, Bezerra e Sales (2010, p. 11), considerando essa diversidade teórica e a característica poligênica das superfícies de aplainamento nordestinas, o entendimento das diversas teorias se mostram necessário, "haja vista que todos os fatores dinâmicos que atuam em sua modelagem (back-wearing e down-wearing), são bastante variáveis na escala temporo-espacial".

Pertinente à morfodinâmica do local, os principais agentes associados são o escoamento superficial e a desagregação mecânica das rochas somado, ainda, às ações de processos bioquímicos (RIBEIRO; MARÇAL; CORREA, 2010). É conveniente, ainda, 
HENRIQUES, D. S.; SOUZA, A. C. N.; SOUZA, S. D. G.; SOUSA, M. L. M.

Heranças da paisagem semiárida: Os relevos residuais de Alexandria-RN, Brasil.

ressaltar que a atuação dos processos morfogenéticos atuantes ocorrem conforme a especificidade climática dominante, a proteção e resistência do solo por meio da cobertura vegetal presente e, por fim, o controle litológico da área.

Segundo Ribeiro, Marçal e Correa (2010), os processos bioquímicos de intemperismo, consoante as condições de cobertura vegetal (grau de proteção do solo) e pluviométricas, com chuvas esporádicas e intensas, influem no surgimento de superfícies aplainadas correlacionadas à inselbergs - formas de relevo típicas e que dominam áreas semiáridas.

Lima et al. (2009) entendem os inselbergs como elevações rochosas e isoladas por extensas planícies, tomando formas de verdadeiras ilhas terrestres. Ainda segundo esses autores, as rochas que os formam são de origem plutônica intrusiva ou plutônica metamorfizada. Assim, as rochas que sustentam esses monumentos são provenientes do magma cristalizado, consolidado à grandes profundidades da superfície terrestre e submetidas a altas pressões e temperaturas.

Freise (1938, apud Lima et al., 2009, p. 40), um dos pioneiros ao estudar a petrografia e mineralogia dos inselbergs, com base em seu trabalho realizado na região Nordeste do Brasil, admite que tanto a diferença do material geológico entre os inselbergs e a superfície circuncidante quanto controle estrutural geológico intervém na formação dos dessas formações, em razão de, comumente, "esses monumentos estarem alinhados na direção da orientação do tectonismo regional”.

A partir da corrosão de uma cadeia montanhosa esses relevos residuais tem sua origem, podendo ser fonte de dados e informações valorosas sobre a evolução geomorfológica dos terrenos em que ocorrem (MAIA et al., 2015). Em outros termos, os inselbergs são retratos de resistência a agentes físicos e químicos da natureza, bem como das intempéries climáticas as quais foi submetido por milhões e milhões de anos.

Nessa perspectiva, os inselbergs, sendo uma forma escultural reflexo de uma estrutura de minerais mais resistentes aos processos intempéricos (RIBEIRO, MARÇAL; CORREA, 2010), e que já fez parte de um complexo litológico maior, podem ser julgados como heranças paisagísticas advindas das marcas do tempo de eras geológicas passadas. 
HENRIQUES, D. S.; SOUZA, A. C. N.; SOUZA, S. D. G.; SOUSA, M. L. M.

Heranças da paisagem semiárida: Os relevos residuais de Alexandria-RN, Brasil.

\section{UM ESTUDO EM ALEXANDRIA-RN: LOCALIZAÇÃO E CARACTERIZAÇÃO}

O município de Alexandria situa-se na região imediata de Pau dos Ferros, à oestedo Estado potiguar, como mostra a Figura 02. Apresenta uma extensão territorial de aproximadamente $419 \mathrm{~km}^{2}$ e uma população de 13.507 pessoas com densidade, demográfica de 35,43 hab/km2 (IBGE, 2010). Em relação ao perfil socioeconômico, o município aponta um Produto Interno Bruto (PIB) per capita de 8.581,87 reais e um Índice de Desenvolvimento Humano Municipal (IDHM) de 0,606 (IBGE).

Figura 2: Localização do município em estudo

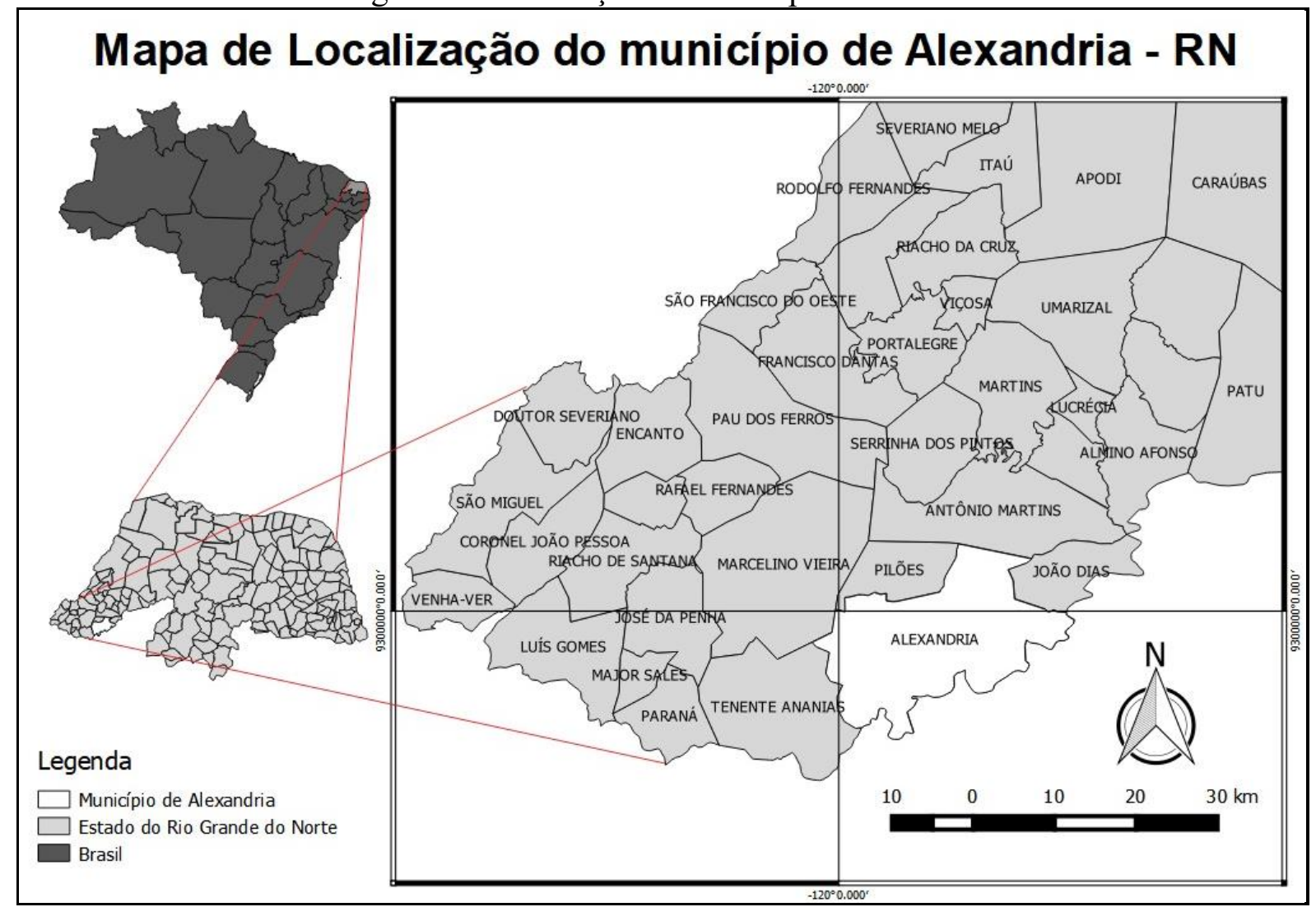

Fonte: Autores, 2019.

Do ponto de vista fisiográfico, a área em estudo está inserida na Província Borborema, constituída por litotipos do Complexo Caicó, granitóides das suítes Poço da Cruz e Itaporanga e por granitóides diversos de quimismo indiscriminado (CPRM, 2005). Com pluviometria de 886,6 mm, segundo a Empresa de Pesquisa Agropecuária do Rio Grande do Norte - EMPARN, 1963 a 2006, Alexandria faz parte da Bacia Hidrográfica do Rio Apodi Mossoró e tem uma grande concentração de açudes que servem de abastecimento à 
HENRIQUES, D. S.; SOUZA, A. C. N.; SOUZA, S. D. G.; SOUSA, M. L. M.

Heranças da paisagem semiárida: Os relevos residuais de Alexandria-RN, Brasil.

população, para suprirem o déficit hídrico da região semiárida, bem como a perfuração de poços, no domínio hidrológico fissural, que totalizam 439 (IDEMA, 2018).

O município abriga belas paisagens do sertão potiguar, pelo conjunto paisagístico que apresenta, principalmente referente aos relevos residuais dos inselbergs, em virtude das suas condições geoambientais.

\section{HERANÇAS DA PAISAGEM EM ALEXANDRIA-RN: OS INSELBERGS}

No nordeste setentrional brasileiro, situam-se vários campos de inselbergs, exumados por fatores erosionais ao longo do tempo. São múltiplas as teorias que tentam desmistificar a evolução geomorfológica do Nordeste brasileiro. Nesse quadrante entra a participação dos relevos residuais, como os inselbergs, que servem como fonte de dados primários para conhecer mais acerca dos relevos em eras geológicas passadas e as dinâmicas atuais que ainda atuam sobre a superfície terrestre. Essas formações estão associadas a um embasamento ígneo, oriundo de intrusões graníticas ocorridas durante o Pré-cambriano e que afetaram de modo significativo a província da Borborema (MAIA et al., 2015).

Esses tipos de feições geomorfológicas são possíveis de serem encontradas no extremo oeste do Estado do Rio Grande do Norte, mais precisamente nos limites do município de Alexandria. Junto das formações de inselbergs, aparecem, ainda, extensas áreas de lajedos que conferem uma paisagem exuberante no interior do sertão nordestino.

Para este trabalho, dois pontos de análise foram selecionados no município supracitado. Um desses pontos foi o inselberg, denominado de Serra Barriguda, e o outro é um extenso lajedo localizado no Sítio Lajes. Ambas as formações não possuem relevos superiores a 560 metros.

As tipologias dessas formações se assemelham, respectivamente, aos castellated (castelos) e aos bornhardts, segundo a classificação que Lima et al. (2009) apresentam em seu livro sobre os inselbergs. Segundo esses autores, os tipos castelos são formações imponentes, modelados por falhas e fraturas verticais, semelhantes a "paredes" íngremes numa planície. Os bornhardts, por sua vez, são aquelas formações que possuem superfície mais arredondas e alongadas.

Ainda segundo o escrito desses autores, é possível afirmar que, por serem formações descendentes de intrusões plutônicas, possuem dois principais minerais 
HENRIQUES, D. S.; SOUZA, A. C. N.; SOUZA, S. D. G.; SOUSA, M. L. M.

Heranças da paisagem semiárida: Os relevos residuais de Alexandria-RN, Brasil.

constituintes: os félsicos e os máficos. Em conformidade com o Glossário [on-line] da Diretoria de Geologia (Mineropar), do Instituto de Terras, Cartografia e Geologia do Paraná (ITCG), o termo "félsico" é uma denominação aplicada a minerais, magmas e rochas enriquecidos em elementos leves, tais como: silício, oxigênio, alumínio e potássio. Além disso, os minerais félsicos são comumente claros, sendo os mais comuns o quartzo, feldspato, a muscovita e o ortoclásio. Já o termo "máfico" é atribuído aos minerais ferromagnesianos, de cor escura, constituintes de rochas ígneas.

A formação que mais se destaca em meio ao conhecimento popular da região é a chamada "Serra Barriguda" (Figura 03), pois, em meio a outras formações graníticas, apresenta sinais claros que apontam para uma origem relacionada a intrusões magmáticas, com a presença de afloramentos rochosos e áreas em que esse tipo de rocha aparece pela denudação através de processos erosivos.

Figura 3: A - Serra da Barriguda; B - Área de relevos residuais associados a inselbergs de Alexandria-RN

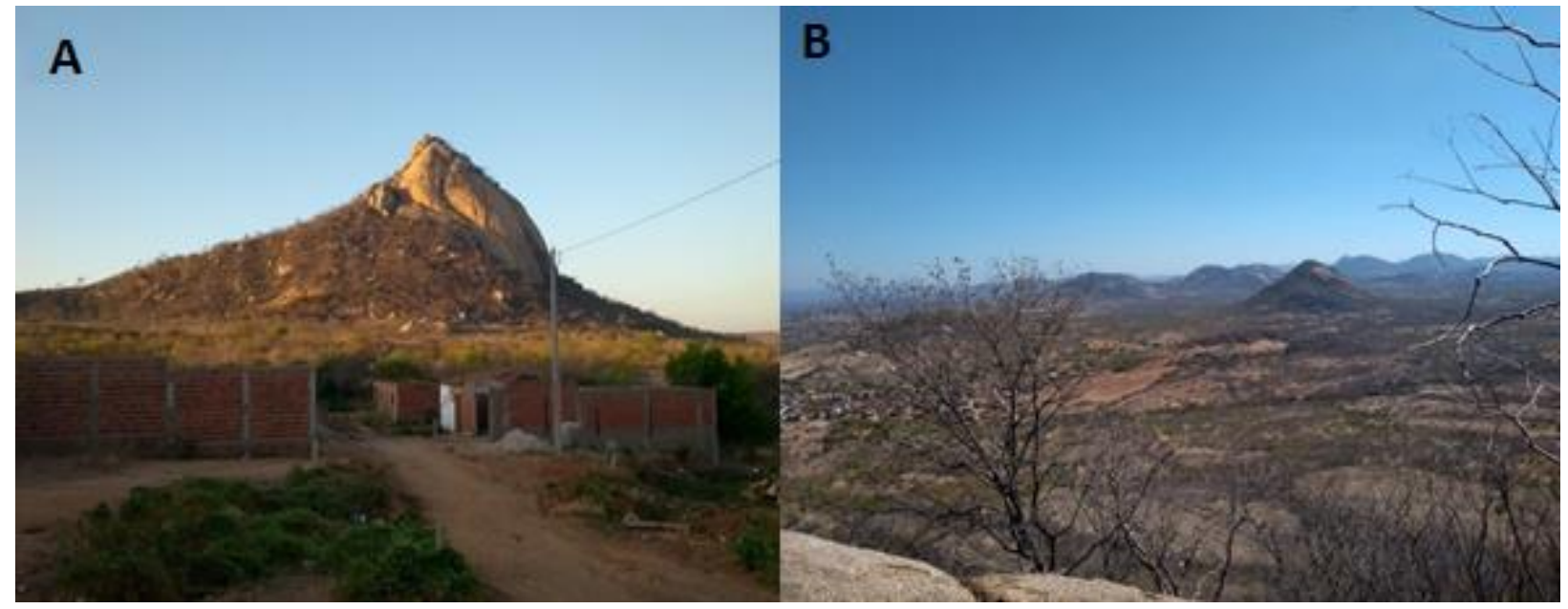

Fonte: Souza, 2019.

Os inselbergs encontrados nessas áreas não apresentam feições geomorfológicas associadas à dissecação por caneluras, karrens ou bacias de dissolução, como dissecações típicas encontradas em outros inselbergs, a exemplos dos casos evidenciados em Quixadá (CE), por Maia e Nascimento (2018). Entretanto, encontra-se feições resultantes de meteorização, com grandes blocos rochosos fragmentados pela ação do intemperismo (Figura 04). 
HENRIQUES, D. S.; SOUZA, A. C. N.; SOUZA, S. D. G.; SOUSA, M. L. M.

Heranças da paisagem semiárida: Os relevos residuais de Alexandria-RN, Brasil.

Figura 4: Blocos de rocha granítica fragmentada por processos de meteorização

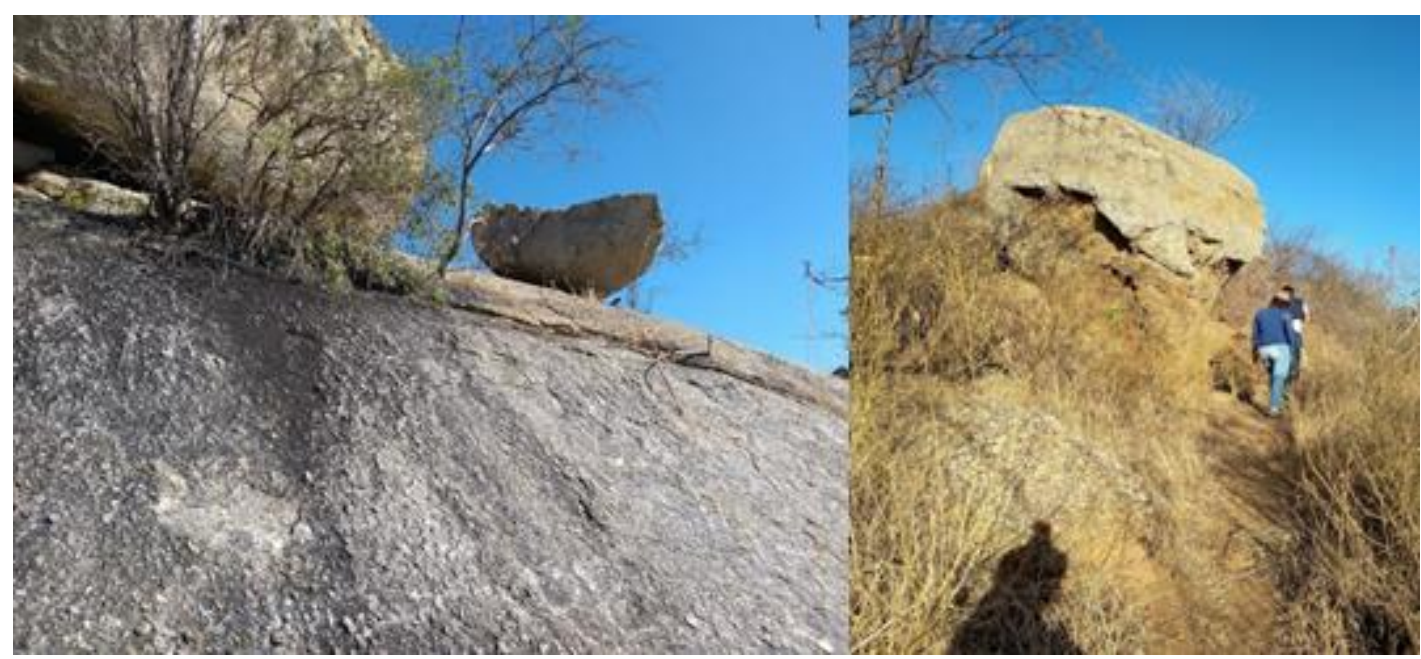

Fonte: Souza, 2019.

Vários sedimentos, grandes blocos rochosos provenientes de processos erosivos, circundam o sopé da Serra Barriguda. Outros blocos se encontram propícios a desabarem, conforme o grau das intempéries naturais, como as fortes e torrenciais chuvas do período chuvoso. Algo preocupante a se ponderar é que a sede do município se localiza bem próximo à Serra e, com o crescimento da mancha urbana, já existem formas de ocupação pela população nas intermediações da base do monumento, além das atividades agropastoris instalada há alguns anos. Conforme mostra a Figura 05, do alto da Serra da Barriguda, a vista paisagística à hinterlândia da cidade.

Figura 5: Visão parcial do cume da Serra da Barriguda de parte de um bairro da cidade

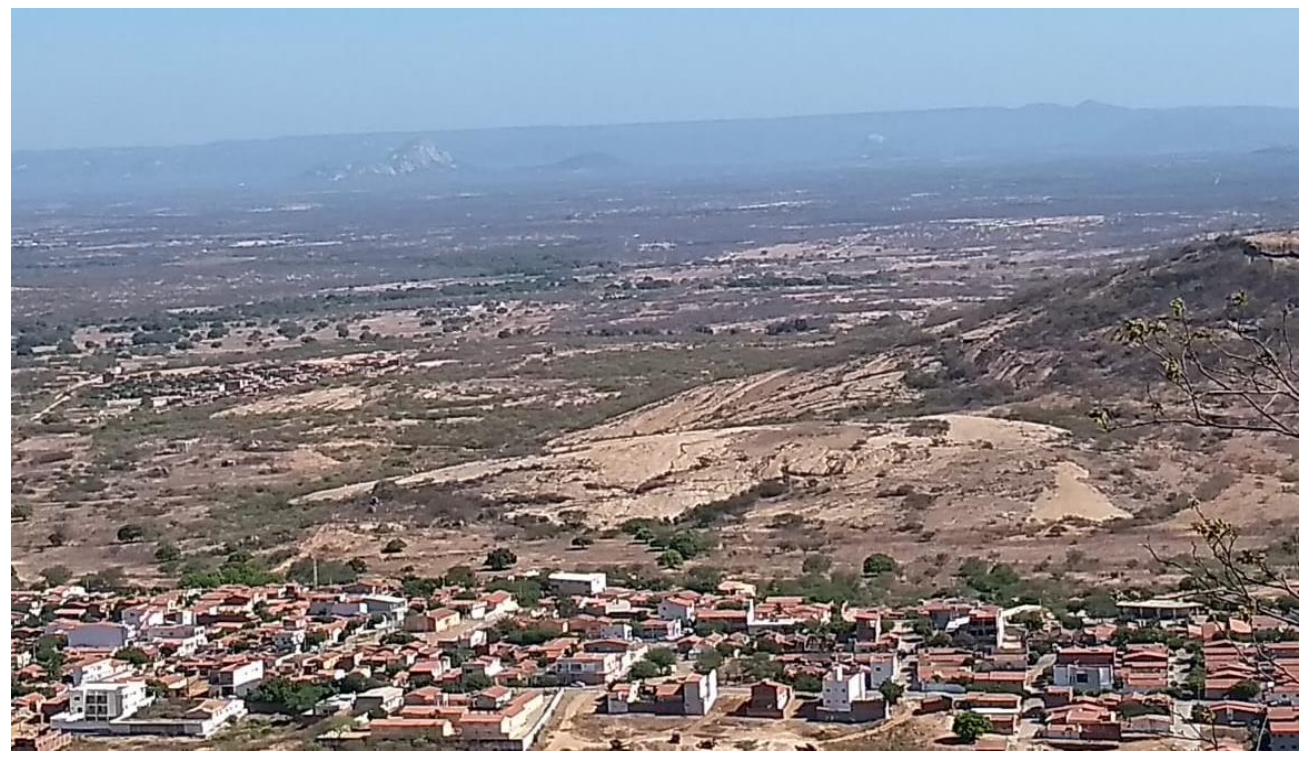

Fonte: Silva, 2019.

Revista Cerrados, Montes Claros/MG, v. 18, n. 02, p. 208-226, jul./dez.-2020. 
HENRIQUES, D. S.; SOUZA, A. C. N.; SOUZA, S. D. G.; SOUSA, M. L. M.

Heranças da paisagem semiárida: Os relevos residuais de Alexandria-RN, Brasil.

Concomitante aos inselbergs, a paisagem se constitui de uma extensa área de lajedos (Figura 06), na qual, pela presença do relevo granítico, as feições estão associadas à intemperização química pela ação da água nos minerais da rocha.

Figura 6: Lajedo com lagoa natural no Sítio Lajes em Alexandria - RN

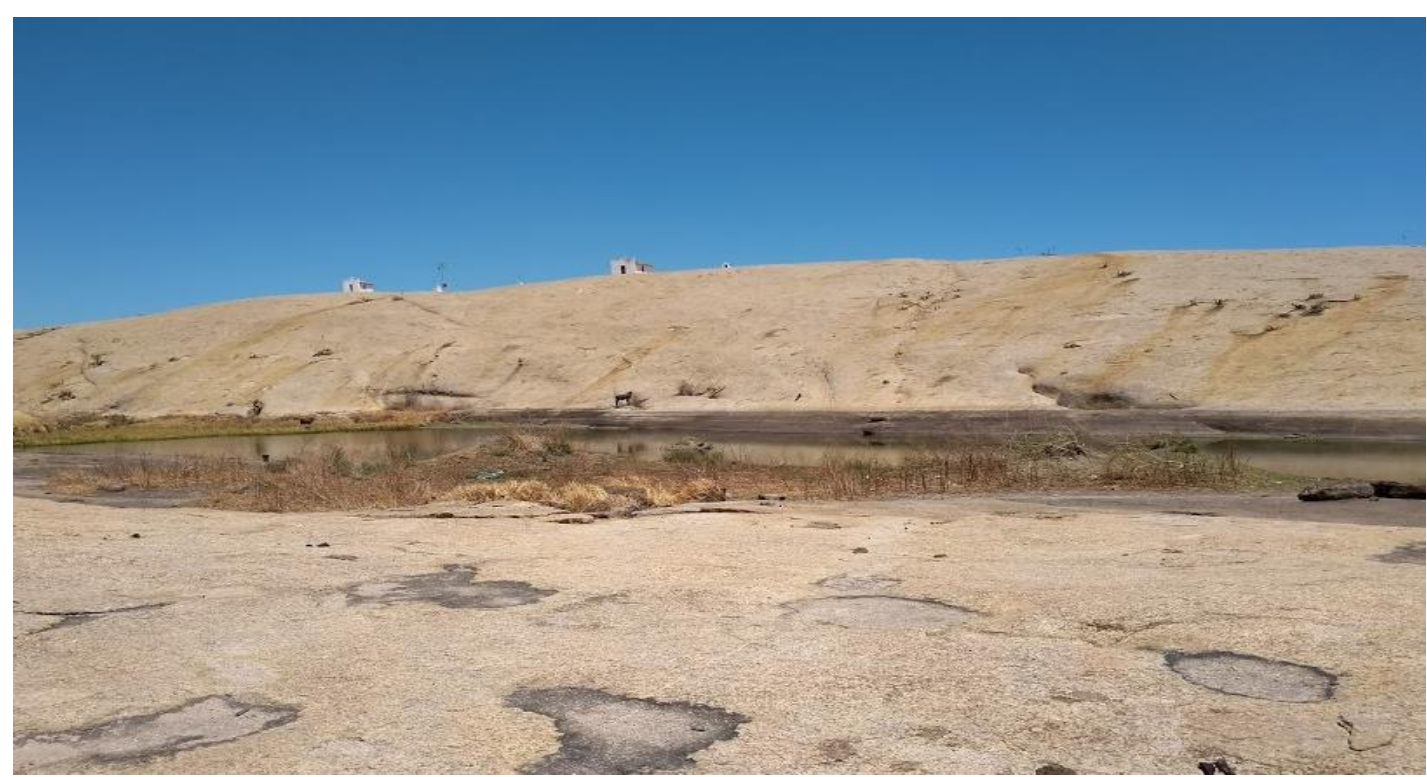

Fonte: Souza, 2019.

Comparando-se à Serra Barriguda, o vasto lajedo do Sítio Lajes é de fácil acesso e se encontra mais distante da sede do município de Alexandria. Porém, a ocupação ali é relativa ao passo que nessa formação existem inclusive símbolos religiosos, como as capelas, e que coabitam com antenas de internet para a população local. Há de se destacar ainda que, nesse ponto, já foram encontrados fósseis de animais pré-históricos, hoje expostos no museu Câmara Cascudo, na cidade de Natal (RN).

$\mathrm{Na}$ configuração desse recorte da paisagem ocorrem feições que podemos associar a bacias de dissolução. Estas são cavidades expostas na superfície granítica, com tamanho variável de centímetros até alguns metros de diâmetro, por isso podem ser pequenas cavidades côncavas ou ovaladas que, quando muito longas, assemelham-se às marmitas (MAIA; NASCIMENTO, 2018).

Entretanto, apesar de possuir condições de gênese e ambiente para ocorrência no lajedo em questão, a maior parte desse tipo de feição encontra-se em estágio inicial, que é quando as cavidades estão ainda em formação, mas é possível encontrar bacias de dissolução, 
HENRIQUES, D. S.; SOUZA, A. C. N.; SOUZA, S. D. G.; SOUSA, M. L. M.

Heranças da paisagem semiárida: Os relevos residuais de Alexandria-RN, Brasil.

propriamente dita, pelo estágio com que a rocha foi dissolvida e adquiriu tal feição (Figura 07).

Figura 7: As imagens representam bacias de dissolução, sendo a do lado esquerdo representativa do estágio inicial do processo de formação das bacias

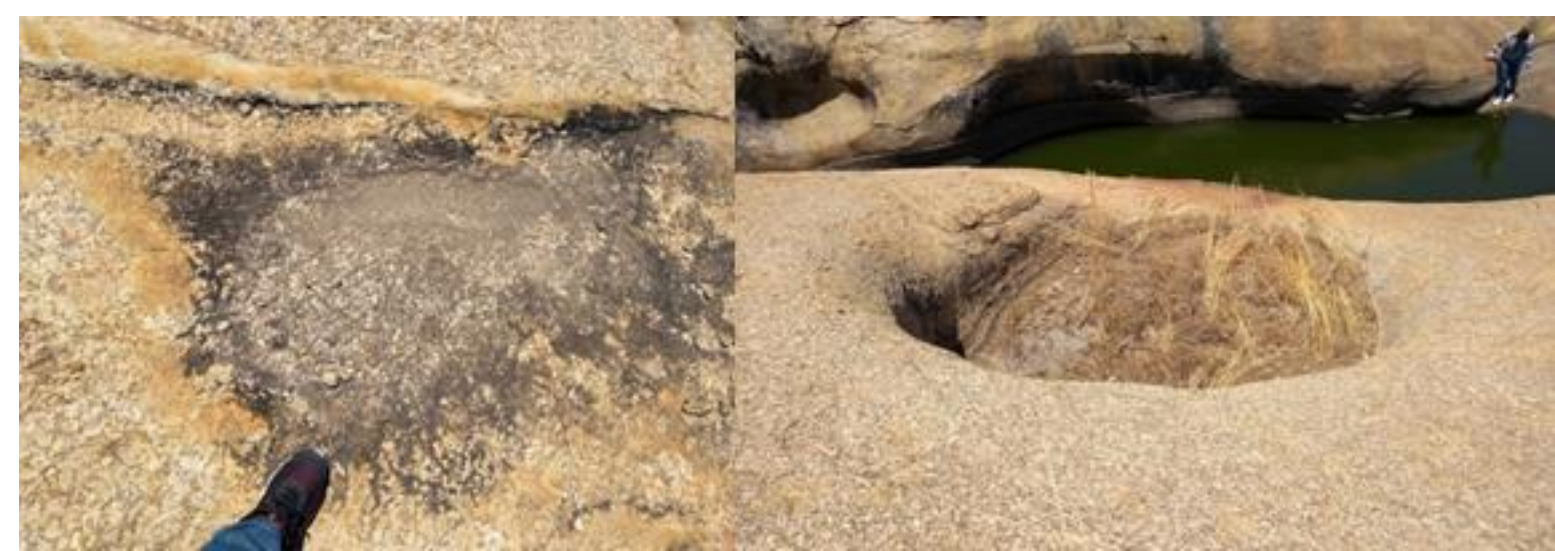

Fonte: Souza, 2019.

Salientamos que, em ambas as formações, a vegetação é edáfica e climaticamente seca. Em geral, a caatinga arbustiva domina as áreas. Para a Serra Barriguda, o sistema radicular das árvores encontra-se expostas devido à pouca profundidade do solo e os processos erosionais das chuvas, marcantes na paisagem local.

Assim, visualizou-se que, a partir da evolução geológica e geomorfológica, o município de Alexandria - RN apresenta marcas expressivas da herança paisagísticas. Indubitavelmente, essas paisagens, além de serem de importância inigualável para a geodiversidade brasileira, são dotadas de potencialidades diversas.

\section{A PAISAGEM SEMIÁRIDA ALEXANDRIENSE E 0 POTENCIAL À GEODIVERSIDADE: BREVES CONSIDERAÇÕES}

A geodiversidade é um conceito relativamente novo e interdisciplinar às ciências, tendo surgido em meados dos anos 90 do século XX, representando toda a natureza abiótica (substratos terrestres que não possuem vida), como aspectos geológicos e geomorfológicos. É válido salientar, ainda, que este conceito surge conexo ao de biodiversidade que, por sua vez, expressa toda a diversidade biótica (que possui vida) da natureza. 
HENRIQUES, D. S.; SOUZA, A. C. N.; SOUZA, S. D. G.; SOUSA, M. L. M.

Heranças da paisagem semiárida: Os relevos residuais de Alexandria-RN, Brasil.

Para o Serviço Geológico do Brasil (SBG) da Companhia de Pesquisa de Recursos Minerais (CPRM, 2010, p.15), por exemplo, identifica a geodiversidade como o um ambiente físico-abiótico, representado significativamente por um ambiente diversificado, incluindo tanto os materiais, fenômenos e processos que o deram origem a paisagem, como os elementos que atualmente a compõem expressos pelas "rochas, minerais, águas, fósseis, solos, clima e outros depósitos superficiais que propiciam o desenvolvimento da vida na Terra, tendo como valores intrínsecos a cultura, o estético, o econômico, o científico, o educativo e o turístico".

O termo manifesta-se com o objetivo de assegurar a geoconservação e utilização sustentável do geopatrimônio (patrimônio geológico), de modo a garantir a permanência desses elementos da natureza para as gerações futuras. Os ambientes geodiversos também podem ser considerados espaços de promoção de educação e pesquisas científicas, bem como áreas de lazer propícias a atividades do geoturismo.

Logo, a geodiversidade da paisagem de Alexandria é dotada de potencialidades, mas também de limitações, conforme apontam Oliveira e Sousa (2018). Dentre essas potencialidades paisagísticas, elenca-se o turismo de contemplação, a presença de nascentes de água, atividades de esportes radicais, como o rapel, rochas profícuas à construção civil, solos férteis, presentes nas encostas dos inselbergs, possíveis sítios paleontológicos/geológicos e até mesmo o refúgio para animais silvestres.

Pertinente as limitações, esses ambientes possuem ecossistemas relativamente frágeis que são comprometidos pelas atividades humanas que circundam o entorno, contribuindo deveras para degradar com desmatamentos e queimadas para áreas de cultivo e ocupação, incidindo na depredação da fauna que buscam abrigar-se nesses lugares.

Além disso, por serem locais públicos e atrativos para visitação turística e sem qualquer meio legal de preservação, induzem intenções propensas às especulações capitalistas. Não são raros os lotes de terrenos disponível ao mercado imobiliário nas intermediações da Serra Barriguda, principalmente por encontrar-se mais próxima da mancha urbana da sede municipal.

São áreas com alto potencial para o geoturismo que recebem, constantemente, aventureiros advindos tanto do município, quanto de regiões próximas, e, embora sejam locais de interesse geológico relativo, encontram-se expostos à depredação humana. Em especial, ainda no inselberg da Barriguda, os blocos de rochas desse ambiente são pintados pelos 
HENRIQUES, D. S.; SOUZA, A. C. N.; SOUZA, S. D. G.; SOUSA, M. L. M.

Heranças da paisagem semiárida: Os relevos residuais de Alexandria-RN, Brasil.

turistas que visitam a área, e ainda não existe nenhum órgão público do município que se responsabilize pelo monitoramento e aproveitamento sustentável desses locais.

No entanto, esses ambientes carecem de estudos aprofundados, de modo que fomente a pesquisa e visitação por parte de estudantes locais. Outrossim, são pontos que, se utilizados de maneira correta, poderiam incrementar ainda mais nos índices socioeconômicos do município.

\section{CONSIDERAÇÕES FINAIS}

A partir do estudo realizado, podemos considerar que o semiárido nordestino é constituído por quadros paisagísticos diversos, ocupados por variadas formas de relevo que se comportam como resultado do tempo e processos históricos. A gênese geomorfológica dessa paisagem tem sido alvo de pesquisas que, através de teorias adequadas, explicam as reais dinâmicas que modelaram e/ou deram origem as formas de relevos atuais.

Pertinente aos relevos residuais analisados, ambos são constituídos de minerais félsicos (principalmente, quartzos e feldspato) que atribuem as rochas uma tonalidade mais clara, e os minerais máficos uma coloração mais escura. Logo, a porosidade das rochas das duas formações não é muito expressiva e, assim, compõe a resistência dos inselbergs.

É válido ressaltar, ainda, que as formações - incluindo o caso do Sítio Lajes, como um verdadeiro baú que armazena objetos preciosos, a exemplo dos fósseis já encontrados, - merecem estudos mais avançados e pormenorizados subsidiado por outras ciências. Dessa forma, asseguraria a importância e preservação do local e, quiçá, a implementação de um Sítio Geológico-Geomorfológico. Tal fato fortaleceria as premissas do turismo ecológico, geomorfológico e sustentável, centrado na educação ambiental defendida pelo conceito de geoturismo.

A importância da implementação dessas formações, como uma unidade de preservação, seria deveras necessária por observar-se que a ação antrópica é tendenciosa na área das duas formações. Por serem pontos turísticos do município, atraem muitos visitantes, resultando em possíveis áreas de especulação imobiliária onde, são, inclusive, extensas as áreas desmatadas para ocupação principalmente no entorno da Serra Barriguda. É preocupante, ainda referente à essa Serra, a quantidade de lixo descartado ao longo da trilha ao topo. 
HENRIQUES, D. S.; SOUZA, A. C. N.; SOUZA, S. D. G.; SOUSA, M. L. M.

Heranças da paisagem semiárida: Os relevos residuais de Alexandria-RN, Brasil.

Assim, através do estudo de caso realizado no município de Alexandria - RN, bem como por meio das leituras sobre as paisagens semiáridas do Nordeste brasileiro, é possível afirmar que os relevos residuais são heranças dispostas nas feições geomorfológicas e marcam a paisagem semiárida do sertão do oeste potiguar nordestino.

Por fim, consideramos que a paisagem analisada realça os potenciais de geodiversidade, e é passível de ser palco de pesquisas científicas futuras sob outras perspectivas de análise e abordagem, respeitando os princípios da educação ambiental, possibilitando fomentar o desenvolvimento do território alexandriense.

\section{REFERÊNCIAS}

AB'SABER, A. N. Caatingas: O domínio dos sertões secos. In: Os domínios de natureza no Brasil: potencialidades regionalistas. São Paulo: Ateliê Editorial, p. 83-100, 2003.

BERTRAND, G. Paisagem e Geografia Física Global: esboço metodológico. Tradução: Olga Cruz. RA'E GA. Editora UFPR, Curitiba, n. 8, p. 141-152, 2004. Disponível em: calvados.c3sl.ufpr.br/ojs2/index.php/raega/article/viewPDFInterstitial/3389/2718. Acesso em: Abril de 2020.

BRASIL. Instituto Brasileiro de Geografia e Estatística. Cidades @. 2019. Disponível em: https://cidades.ibge.gov.br/brasil/rn/alexandria/panorama. Acesso em: Outubro de 2019.

CORREIA, R. C. et al. A região semiárida brasileira. In: VOLTOLINI, T. V. Produção de caprinos e ovinos no Semiárido. Petrolina: Embrapa Semiárido, p. 21-48, 2011. Disponível em: https://ainfo.cnptia.embrapa.br/digital/bitstream/item/54762/1/01-A-regiao-semiaridabrasileira.pdf-18-12-2011.pdf. Acesso em: Abril de 2020.

CPRM. Serviço Geológico do Brasil. MASCARENHAS, J. C. et al (Org.). Projeto cadastro de fontes de abastecimento por água subterrânea. Diagnóstico do Município de Alexandria, estado do Rio Grande do Norte. Recife: CPRM/PRODEEM, 2005. Disponível em:

http://rigeo.cprm.gov.br/xmlui/bitstream/handle/doc/16226/rel_alexandria.pdf?sequence=1. Acesso em: Abril de 2020.

CPRM. Serviço Geológico do Brasil. PFALTZGRAFF, P. A. S.; TORRES, F. S. M.

Geodiversidade do estado do Rio Grande do Norte. Recife: CPRM, 2010. Disponível em: http://rigeo.cprm.gov.br/jspui/bitstream/doc/16773/1/Geodiversidade_RN.pdf. Acesso em: Abril de 2020.

CUNHA, J. F. et al. Principais solos do Semiárido tropical brasileiro: caracterização, potencialidades, limitações, fertilidade e manejo. In: SÁ, I. B.; SILVA, P. C. G. (Ed.). Semiárido brasileiro: pesquisa, desenvolvimento e inovação. Petrolina: Embrapa Semiárido, 2010. Disponível em: 
HENRIQUES, D. S.; SOUZA, A. C. N.; SOUZA, S. D. G.; SOUSA, M. L. M.

Heranças da paisagem semiárida: Os relevos residuais de Alexandria-RN, Brasil.

http://ainfo.cnptia.embrapa.br/digital/bitstream/item/158421/1/CAPITULO-02-TONYfinal.pdf. Acesso em: Abril de 2020

DUQUE, J. G. Perspectivas nordestinas. 2. ed. Fortaleza: Banco do Nordeste do Brasil, 2004.

GOVERNO DO RIO GRANDE DO NORTE. Empresa de Pesquisa Agropecuária do Rio Grande do Norte. 2019. Disponível em: http://www.emparn.rn.gov.br/. Acesso em: Novembro de 2019.

GOVERNO RIO GRANDE DO NORTE. Instituto de Desenvolvimento Sustentável e Meio Ambiente. 2019. Disponível em: http://www.idema.rn.gov.br/Index.asp. Acesso em:

Novembro de 2019.

GOVERNO DO PARANÁ. Glossário da Diretoria de Geologia (Mineropar) do Instituto de Terras, Cartografia e Geologia (ITCG). 2019. Disponível em:

http://www.mineropar.pr.gov.br/modules/glossario/conteudo.php. Acesso em: Novembro de 2019.

LIMA, G. M. P. et al. Inselberge: Ilhas Terrestres. Salvador: EDUFBA, 2009.

MAIA, R. P.; BEZERRA, F. H. R.; SALES, V. C. Geomorfologia do Nordeste: Concepções clássicas e atuais acerca das superfícies de aplainamento. Revista de Geografia (Recife).

Recife: UFPE - DCG/NAPA, v. especial VIII SINAGEO, n. 1, p. 1-19, Set. 2010. Disponível em: https://periodicos.ufpe.br/revistas/revistageografia/article/view/228857/23268. Acesso em: Abril de 2020.

MAIA, R. P.; NASCIMENTO, M. A. L. Relevo Granítico do Nordeste Brasileiro. Revista Brasileira de Geomorfologia (On-line), São Paulo, v.19, n.2, Abr./Jun. p.373-389, 2018. Disponível em: http://www.lsie.unb.br/rbg/index.php/rbg/article/view/1295/685. Acesso em: Abril de 2020.

MAIA, R. P. et al. Geomorfologia do campo de inselbergs de Quixadá - NE do Brasil. Revista Brasileira de Geomorfologia, São Paulo, v.16, n.2, p.239-253, Abr./Jun., 2015. Disponível em: http://www.lsie.unb.br/rbg/index.php/rbg/article/view/651/469. Acesso em: Abril de 2020.

MARQUES, F. A. et al. Solos do Nordeste. Embrapa: Recife, 2014. Disponível em: https://www.infoteca.cnptia.embrapa.br/infoteca/bitstream/doc/1003864/1/FOLDERSOLOSD ONEversaofinal.pdf. Acesso em: Abril de 2020.

OLIVEIRA, C. C.; SOUSA, M. L. M. Potencialidades e Limitações do Campo de Inselbergs no Alto Oeste Potiguar/RN. 2018. 22 f. TCC (Graduação) - Curso de Geografia, Departamento de Geografia, UERN - CAPF, Pau dos Ferros, 2018.

RIBEIRO, S. C.; MARÇAL, M. S.; CORREA, A. C. B. Geomorfologia de Áreas Semiáridas: uma contribuição ao estudo dos Sertões Nordestinos. Revista de Geografia. Recife: UFPE DCG/NAPA, v. 27, n. 1, p. 120-137, Jan./mar. 2010. Disponível em: 
HENRIQUES, D. S.; SOUZA, A. C. N.; SOUZA, S. D. G.; SOUSA, M. L. M.

Heranças da paisagem semiárida: Os relevos residuais de Alexandria-RN, Brasil.

https://periodicos.ufpe.br/revistas/revistageografia/article/view/228790/23203. Acesso em: Abril de 2020.

SILVA, P. C. G. et al. Caracterização do Semiárido brasileiro: fatores naturais e humanos. In: SA, I. B.; SILVA, P. C. G. da. (Ed.). Semiárido brasileiro: pesquisa, desenvolvimento e inovação. Petrolina: Embrapa Semiárido, 2010. Disponível em: https://www.alice.cnptia.embrapa.br/alice/bitstream/doc/861906/1/CAPITULO01PEDROGA MAfinal.pdf. Acesso em: Abril de 2020.

SOUSA, M. L. M.; OLIVEIRA, V. P. V.; Política de combate à seca e estratégias de convivência com o semiárido: o contexto do estado do Ceará. In: SEABRA, G;

MENDONÇA, I. (Org.). Educação ambiental: Responsabilidade para a conservação da sociobiodiversidade. João Pessoa: Editora Universitária da UFPB, 2011. Disponível em: https://pt.scribd.com/document/403480444/II-CNEA-Educacao-Ambiental-responsabilidadepara-a-conservacao-da-sociobiodiversidade-Vol-1-pdf. Acesso em: Abril de 2020.

SOUZA, M. J. N.; OLIVEIRA, V. P. V. Semiárido do Nordeste do Brasil e o Fenômeno da Seca. In: HUBP, J. L; INBAR, M. Desastres Naturales em América Latina. Cidade do México: Fondo de Cultura, 2002.

\section{Autores}

Diógenys da Silva Henriques - É Graduando em Geografia pela Universidade do Estado do Rio Grande do Norte (UERN). Membro do Grupo de Estudos Análise Geoambiental e Estudos Integrados da Paisagem (GEAGEIP) e do Núcleo de Estudos Geoambientais e Cartográficos (NEGECART).

Anny Caratina Nobre de Souza - É Graduanda em Geografia pela Universidade do Estado do Rio Grande do Norte (UERN). Membra do Grupo de Estudos Análise Geoambiental e Estudos Integrados da Paisagem (GEAGEIP), do Núcleo de Estudos Geoambientais e Cartográficos (NEGECART) e do Núcleo de Estudos em Geografia Agrária e Regional (NuGAR).

Sérgio Domiciano Gomes de Souza - É Graduando em Geografia pela Universidade do Estado do Rio Grande do Norte (UERN). Membro do Grupo de Estudos Análise Geoambiental e Estudos Integrados da Paisagem (GEAGEIP) e do Núcleo de Estudos Geoambientais e Cartográficos (NEGECART).

Maria Losângela Martins de Souza - É Graduada em Geografia pela Universidade Estadual do Ceará (UECE); Metra e Doutra em Geografia pela Universidade Federal do Ceará (UFC). Atualmente é professora Adjunta do departamento de Geografia da Universidade do Estado do Rio Grande do Norte (UERN) e professora permanente do Programa de Pós-Graduação em Planejamento e Dinâmicas Territoriais no Semiárido (PLANDITES/UERN). 
HENRIQUES, D. S.; SOUZA, A. C. N.; SOUZA, S. D. G.; SOUSA, M. L. M. Heranças da paisagem semiárida: Os relevos residuais de Alexandria-RN, Brasil.

Artigo recebido em: 09 de abril de 2020.

Artigo aceito em: 19 de junho de 2020.

Artigo publicado em: 21 de setembro de 2020. 